\title{
Endocannabinoid System Modulates Relapse to Methamphetamine Seeking: Possible Mediation by the Arachidonic Acid Cascade
}

\author{
Kusnandar Anggadiredja', Masanori Nakamichi', Takato Hiranita', Hiroyuki Tanaka², Yukihiro Shoyama ${ }^{3}$, \\ Shigenori Watanabe' and Tsuneyuki Yamamoto*,' \\ 'Department of Pharmacology, Graduate School of Pharmaceutical Sciences, Kyushu University, Fukuoka, Japan; ${ }^{2}$ Department of Medicinal Plant \\ Breeding, Graduate School of Pharmaceutical Sciences, Kyushu University, Fukuoka, Japan; ${ }^{3}$ Department of Medical Resources Regulation, \\ Graduate School of Pharmaceutical Sciences, Kyushu University, Fukuoka, Japan
}

\begin{abstract}
We clarified the modulating action of the endocannabinoid system, and its possible mediation by the arachidonic acid cascade, on the reinstatement of methamphetamine (METH)-seeking behavior, using the intravenous self-administration paradigm in rats. Following 12 days of self-administration of METH, the replacement of METH with saline resulted in a gradual decrease in lever press responses (extinction). Under extinction conditions, METH-priming or re-exposure to cues previously paired with METH infusion markedly increased the responses (reinstatement of drug-seeking). The cannabinoid CBI receptor antagonist, SRI4I7I6A, blocked this behavior. Although the cannabinoid agonist, $\Delta^{8}$-tetrahydrocannabinol (THC), had no effects by itself, coadministration of the agonist and METH at small doses reinstated the drug-seeking behavior. THC attenuated the effects of the reinstatement-inducing dose of METH, but enhanced the effect of cues. Either given repeatedly during the extinction or singly, $24 \mathrm{~h}$ before the first METH-priming or cues challenge, THC suppressed the reinstatement. In another set of experiments, we found that diclofenac, a cyclooxygenase inhibitor, also attenuated the reinstatement induced by exposure to cues or drug-priming. These results suggest that the endocannabinoid system, through possible mediation by the arachidonic acid cascade, serves as a modulator of the reinstating effects of METH-priming and cues. Extending the current view on the treatment of drug dependence, these results indicate that endocannabinoid-activating substances as well as cyclooxygenase inhibitors may be promising as antirelapse agents.

Neuropsychopharmacology (2004) 29, 1470-1478, advance online publication, 7 April 2004; doi:I 0.1038/sj.npp. 1300454
\end{abstract}

Keywords: endocannabinoid system; relapse; methamphetamine; self-administration; arachidonic acid cascade; rats

\section{INTRODUCTION}

Methamphetamine (METH) is a highly addictive psychostimulant (Woolverton et al, 1984; Cho, 1990; Hart et al, 2001), with reinforcing properties that are comparable to those of cocaine (Peltier et al, 1996; Shimosato and Ohkuma, 2000). Over the past several years, METH abuse has significantly risen worldwide, and is becoming increasingly problematic (Greberman and Wada, 1994).

Recently, cumulating evidence has indicated the involvement of the endocannabinoid system in reward circuit in

\footnotetext{
*Correspondence: Dr T Yamamoto, Department of Pharmacology, Graduate School of Pharmaceutical Sciences, Kyushu University, 3-1- I Maidashi, Higashi-ku, Fukuoka 812-8582, Japan, Tel: 81-92-642-6629, Fax: 8I-92-642-6632, E-mail: tyamamot@phar.kyushu-u.ac.jp

Received 21 October 2003; revised 17 February 2004; accepted 2 March 2004

Online publication: 4 March 2004 at http://www.acnp.org/citations/ Npp0304040348I/default.pdf
}

the brain (Yamamoto and Takada, 2000; Gardner, 2002). Early studies have shown that the psychoactive ingredient of marihuana, $\Delta^{9}$-tetrahydrocannabinol (THC), enhanced brain reward, as indicated by its effect of reducing electrical brain stimulation threshold levels in the medial forebrain bundle (Gardner et al, 1988). Furthermore, like other wellknown habit-forming drugs, $\Delta^{9}$-THC was demonstrated to enhance the extracellular dopamine efflux in rewardrelevant brain loci, such as the striatum, nucleus accumbens, and medial prefrontal cortex (Ng Cheong Ton et al, 1988, Chen et al, 1990). The manifestation of the withdrawal syndrome has been clearly demonstrated following cessation of repeated intake of natural (Hutcheson et al, 1998) and synthetic (Aceto et al, 2001) cannabinoids as well as endogenous cannabinoid ligand (Costa et al, 2000) in dependent animals. Crossinteraction observed between cannabinoid and opioid systems (Navarro et al, 2001; Yamaguchi et al, 2001a) further supports the notion that the endocannabinoid system is a component of reward substrates in the brain. 
Using the self-administration paradigm, the cannabinoid system has been indicated to be involved in the maintenance of drug-seeking and -taking behavior, as evidenced by the reduction in the intake of cocaine by pretreatment with the cannabioid agonist WIN55,212-2 in rats selfadministering cocaine (Fattore et al, 1999). In addition, another cannabinoid agonist HU-210 was shown to reinstate the drug-seeking behavior in rats withdrawn from cocaine and heroin self-administration (De Vries et al, 2001; De Vries et al, 2003).

$\Delta^{1}$-THC, via a receptor-mediated mechanism, stimulated the mobilization of arachidonic acid (Hunter and Burnstein, 1997) and induced activation of phospholipase (Hunter et al, 1986; Wartmann et al, 1995). In line with this finding, Shivachar et al (1996) showed that anandamide- and $\Delta^{9}$ THC-evoked arachidonic acid mobilization were blocked by the CB1 receptor antagonist, SR141716A. Further, there was evidence showing that the endogenous cannabinoid ligand 2 -arachidonoylglycerol is the substrate for cyclooxygenase2 to generate substances belonging to the prostaglandins family (Kozak et al, 2000). We recently demonstrated that cannabinoid-induced behavioral suppression is due to the activation of the arachidonic acid cascade (Yamaguchi et al, 2001b), which is mediated by the prostanoid EP3 receptor (Yamaguchi et al, 2004). Moreover, we have shown that prostaglandin $\mathrm{E}_{2}$ attenuated the expression of the SR141716A-precipitated withdrawal syndrome in THCdependent mice (Anggadiredja et al, 2003). This evidence suggests that the arachidonic acid cascade regulates the intracellular action of cannabinoids, and consequently, takes the role of the endocannabinoid in the brain reward system.

Until recently, data on relapse, which is the main hurdle in the treatment of drug dependence, to METH as it relates to the endocannabinoid system have been scarce. To confirm the cannabinoid hypothesis of relapse to METH abuse, which may describe the key role of the endocannabinoid system in reinstating effects of METH and cues, we tested the effects of the psychoactive ingredient of marihuana, $\Delta^{8}$-THC, administered during the expression of 'relapse' as well as extinction phases, in rats selfadministering METH. Further, we tested the possible involvement of the arachidonic acid cascade, downstream of the endocannabinoid system, in this reinstating effect of METH and cues.

\section{MATERIALS AND METHODS}

\section{Subjects and Apparatus}

Male Wistar/ST (SLC, Hamamatsu, Japan) rats (250-350 g) were used. Under general anesthesia with sodium pentobarbital $(35 \mathrm{mg} / \mathrm{kg})$, silascone ${ }^{\circledR}$ catheters (inner and outer diameter: 0.5 and $1.0 \mathrm{~mm}$, respectively; Kaneka Medix Corporation, Japan) were implanted into the jugular vein and threaded down towards the right atrium. The catheter passed through the skin in the mid-scapular region and was fixed by ligature. The distal portion of the catheter was anchored by a mesh button fixed under the skin on the back. Procedures for animal treatments were conducted in accordance with the Guide for the Care and Use of Laboratory Animals as adopted and promulgated by the
Declaration of Helsinki and Faculty of Pharmaceutical Sciences, Kyushu University Publication, enacted 1988. The distal end of the catheter was connected to a syringe-driven pump containing METH or saline solution. To allow free movement of the rat during experimental sessions, the catheter was connected to a swivel. For the maintenance of catheter patency, before and after each session, the catheter was flushed with $0.15 \mathrm{ml}$ of heparin solution $(30 \mathrm{U} / \mathrm{ml})$. The operant chambers were equipped with an active lever programmed by computer software (Med Associates, Georgia, Vermont).

\section{Drugs}

Methamphetamine $\mathrm{HCl}$ (DaiNippon, Osaka, Japan) was dissolved in saline. THC (kindly provided by Professor Y Shoyama, Department of Medical Resources Regulation, Graduate School of Pharmaceutical Sciences, Kyushu University) was emulsified in $1 \%$ Tween-80 solution. SR141716A (Sanofi Recherche, France) was dissolved in a mixture of Tween-80 and DMSO (Tween-80 and DMSO content in vehicle, $\pm 1 \%$ by volume) and diluted with distilled water. Diclofenac sodium (Sigma, St Louis, MO, USA) was dissolved in saline. Except for the intravenously self-administered METH, all drugs were administered intraperitoneally, and injected at a volume of $0.1 \mathrm{ml}$ per $100 \mathrm{~g}$ of body weight.

\section{METH-Induced Reinstatement of METH-Seeking Behavior}

Self-administration training sessions started 2 days after surgery. Rats were allowed to administer METH $(0.02 \mathrm{mg} /$ infusion over $6 \mathrm{~s}$ ) during a 2-h session, under fixed-ratio 1 (FR-1) schedule of reinforcement, performed each day for 12 days. The chamber light was switched on throughout the session. When the rat pressed the lever, the infusion pump was switched on for $6 \mathrm{~s}$. The subsequent $20 \mathrm{~s}$ was the time out period during which lever presses were still recorded but not accompanied with infusions, and the lever light (mounted $2 \mathrm{~cm}$ above the lever) was switched off. Subsequently, they entered an extinction phase, during which lever presses only resulted in saline infusions. Reinstatement tests started from day 6 of extinction. The test sessions, lasted for $2 \mathrm{~h}$, were carried out under the same conditions as in the extinction phase, in which only saline infusion was available. All drug pretreatments began $30 \mathrm{~min}$ before the session. Drugs were administered in a counterbalanced order every 3-4 days.

\section{METH-Associated Cue-Induced Reinstatement of METH-Seeking Behavior}

Drug self-administration training was carried out on an FR3 schedule of reinforcement. During this training, each earned METH infusion ( $0.02 \mathrm{mg}$ over $6 \mathrm{~s}$ ) was accompanied by the presentation of lever light (300 lux) and tone $(70 \mathrm{~dB} /$ $7 \mathrm{kHz}$ ). The presentation of these cues continued through the subsequent $20 \mathrm{~s}$ time out period, during which lever presses were still recorded but not accompanied with infusions. The 12-day training phase was followed by extinction training, in which neither drug nor cues were 
available. Test sessions began on day 6 of extinction. Each session lasted for $2 \mathrm{~h}$ in total, and was divided into two periods. During the first hour (non-cue phase), the conditions were similar to those in the extinction phase. In the second hour (cue phase), the conditions were similar to those in the self-administration training; however, only saline infusions were available. At the beginning of this cue phase, lever light was switched on for $20 \mathrm{~s}$. Drug pretreatments, administered in a counterbalanced order every 3-4 days, began $30 \mathrm{~min}$ before the second hour of the test sessions.

\section{Effects of THC Given During the Extinction Phase on Reinstatement}

During the extinction phase, one group of rats received THC injection after each daily session for 5 days. On day 6 of the phase, they were then challenged with METH-priming or re-exposed to METH-associated cues. In another group, rats were given only a single THC pretreatment, $24 \mathrm{~h}$ prior to the challenge; and in this group, the challenges were repeated on days 12,20 , and 30 of extinction.

\section{Effects of Diclofenac on Operant Task Performance}

Initially, all subjects were trained to lever press for food on an FR-1 schedule of reinforcement consisting of one food pellet (45 mg; Bioserve ${ }^{\circledR}$, Holton Industries Co., Frenchtown, NJ). Each session ended when a subject has delivered 30 food pellets or the $1200 \mathrm{~s}$ experimental time was over. When the rats have been able to deliver 30 pellets within $600 \mathrm{~s}$, subsequently, they were trained on an FR-3 schedule of reinforcement. The rats were considered ready for tests when they have been able to deliver 30 food pellets within $300 \mathrm{~s}$ in three consecutive training sessions. Each test session ended when a rat has delivered 20 food pellets or the $900 \mathrm{~s}$ experimental time was over.

\section{Statistical Analyses}

In the statistical analyses, drug treatment was a between subjects variable. One-way ANOVA was used to compare means and Benferroni/Dunn tests were used for post hoc. In METH-associated cue-induced reinstatement tests, number of lever presses obtained from the first hour (non-cue phase) was compared with that of the second hour (cue phase) of each session using paired $t$-test. A difference was considered significant at $p<0.05$.

\section{RESULTS}

METH Self-Administration and Extinction Training and Reinstatement of METH-Seeking Behavior

During the self-administration training, the responses gradually increased, and remained stable from day 8 of the training. On the first day of self-administration training the number of infusions was $11.46 \pm 1.80$. This number gradually increased, reaching $16.10 \pm 0.98$ on day 12 of the training. The total number of responses during this selfadministration training was $172.62 \pm 12.19 \mathrm{METH}$ infusions. When the drug was replaced with saline, the lever press responses gradually decreased from $30.75 \pm 6.57$ on the first day, reaching $7.42 \pm 1.75$ lever presses on day 5 of extinction. Under extinction condition, one-way ANOVA revealed a significant main effect of $\mathrm{METH}$ priming $(\mathrm{F}(2,18)=34.26, p<0.0001)$. Post hoc analyses (Benferro$\mathrm{ni} /$ Dunn) showed that injection of $\mathrm{METH}$ at $1 \mathrm{mg} / \mathrm{kg}$ produced a significant increase in lever responses during the $2 \mathrm{~h}$-test sessions (see Figure 1a). In the same way, paired $t$ test showed that, compared with responses obtained during first hour (non-cue), cues previously paired with METH-infusion produced a significant increase in lever responses $(p<0.0001)$ during the second hour of the test sessions (see Figure 1b). Furthermore, both METH-priming and re-exposure to cues still significantly reinstated drugseeking behavior when the animals were re-challenged on days 12, 20, and 30 of extinction (see Figure $5 b$ and c).

\section{Effects of SR141716A on METH-Priming- and Cue-Induced Reinstatement}

There was a significant main effect of SR141716A on reinstatement of $\mathrm{METH}$-seeking behavior induced by METH-priming $(\mathrm{F}(2,18)=30.67, p<0.0001)$. Post hoc analyses (Benferroni/Dunn) revealed that $3.2 \mathrm{mg} / \mathrm{kg}$ SR141716A produced a significant decrease in lever responses (see Figure 2a). As depicted in Figure 2b, one-way ANOVA also revealed a significant main effect of the antagonist on reinstatement induced by re-exposure to METH-associated cues $(\mathrm{F}(1,14)=49.41, \quad p<0.0001)$. Subsequent pairwise analyses (Benferroni/Dunn) showed that $1 \mathrm{mg} / \mathrm{kg}$ SR141716A significantly decreased this cue-induced reinstatement.

\section{Reinstatement-Inducing Effect of THC}

As shown in Figure 3, THC by itself (priming) failed to produce reinstatement at any doses tested, albeit it tended
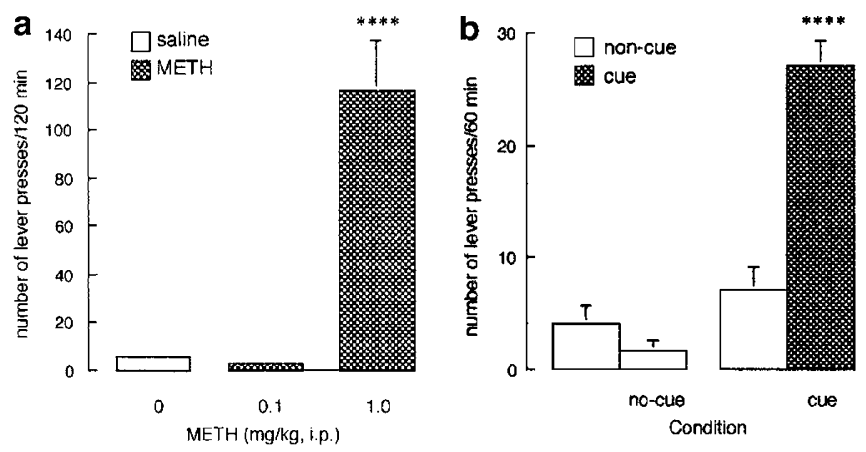

Figure I Reinstatement of METH-seeking behavior induced by METHpriming injection and METH-associated cues. Following METH selfadministration training for 12 days, the rats entered extinction phase (only saline infusion was available). Reinstatement tests started on day 6 of extinction. (a) METH-priming injection $30 \mathrm{~min}$ prior to the test session (lasted for $2 \mathrm{~h}$ ) reinstated METH-seeking behavior, indicated by the significant increase in the number of lever press responses. Data represent the average \pm SE number of lever presses, with 5-8 rats per group; ******* $<0.000$ I compared with saline-treated rats. (b) Re-exposure to $\mathrm{METH}$-associated cues, also produced reinstatement of METH-seeking behavior, indicated by the increased responses during the second hour (cue phase) of the test session. Data represent the average \pm SE number of lever presses, with 5-8 rats per group; ****** $p<0.000$ I compared with the first hour (non-cue phase) of the test session. 
a

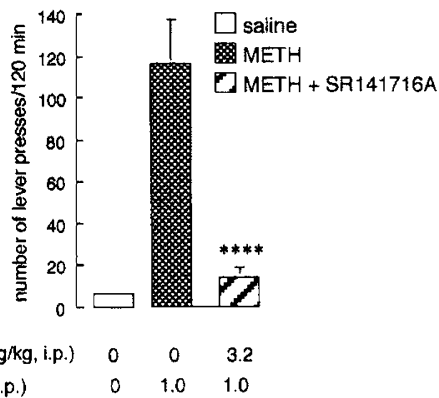

$\begin{array}{llcc}\text { SR } 141716 \text { A (mg/kg, i.p.) } & 0 & 0 & 3.2 \\ \text { METH (mg/kg, i.p.) } & 0 & 1.0 & 1.0\end{array}$

b
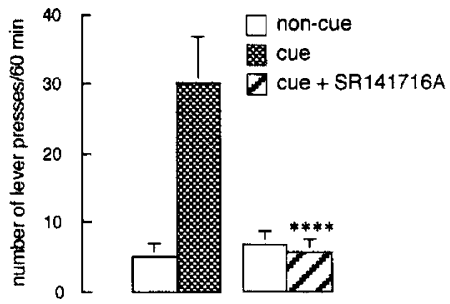

SA141716A (mg/kg, i.p.)

Condition

1.0

Figure 2 Effects of the selective CBI receptor antagonist SRI4I7I6A on reinstatement of $\mathrm{METH}$-seeking behavior in rats. (a) Coadministered with METH $30 \mathrm{~min}$ before the test session, $3.2 \mathrm{mg} / \mathrm{kg}$ SRI4I7/6A produced decreased number of lever press responses, which were significantly different from those produced by METH alone. Data represent the average \pm SE number of lever presses, with 5-8 rats per group; ******* $p<0.0001$ compared with only METH-treated group. (b) This antagonist at $1.0 \mathrm{mg} / \mathrm{kg}$ also suppressed the reinstatement of $\mathrm{METH}$ seeking behavior when administered 30 min prior to the second hour (cue phase) of the test session. Data represent the average \pm SE number of lever presses, with 5-8 rats per group; ****** $<0.000$ I compared with the cue session in only saline-treated rats.

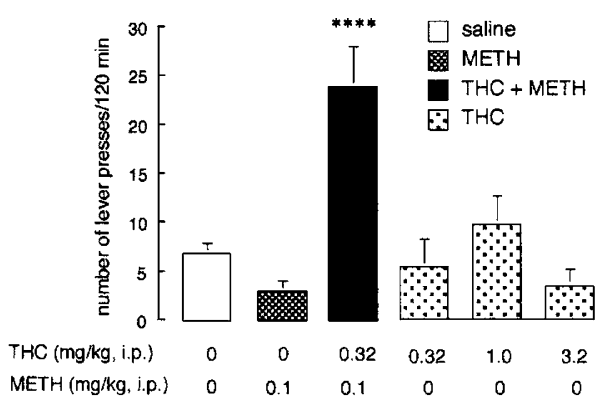

Figure 3 Effects of the cannabinoid agonist $\mathrm{THC}$ in METH selfadministering rats. Although $\mathrm{THC}$, in place of $\mathrm{METH}$-priming, failed to induce reinstatement, there was a tendency for $\mathrm{METH}$ seeking after I mg/kg THC. While each of the drug by itself induced no behavioral consequences, coinjection of i.p. THC $(0.32 \mathrm{mg} / \mathrm{kg})$ and METH $(0.1 \mathrm{mg} / \mathrm{kg})$ significantly increased lever press responses. Data represent average \pm SE number of lever presses. ***** $p<0.000$ I compared with only saline-, $\mathrm{THC}(0.32 \mathrm{mg} / \mathrm{kg})$ or METH $(0.1 \mathrm{mg} / \mathrm{kg})$-treated group. There were $5-7$ rats in each group.

to increase the number of responses at $1 \mathrm{mg} / \mathrm{kg}$. However, coadministered with METH at $0.1 \mathrm{mg} / \mathrm{kg}$, which induced no behavioral consequences, and even reinstatement, $0.32 \mathrm{mg} / \mathrm{kg}$ THC produced a significant increase in lever responses $(\mathrm{F}(3,22)=16.56, p<0.0001$, one-way ANOVA $)$.
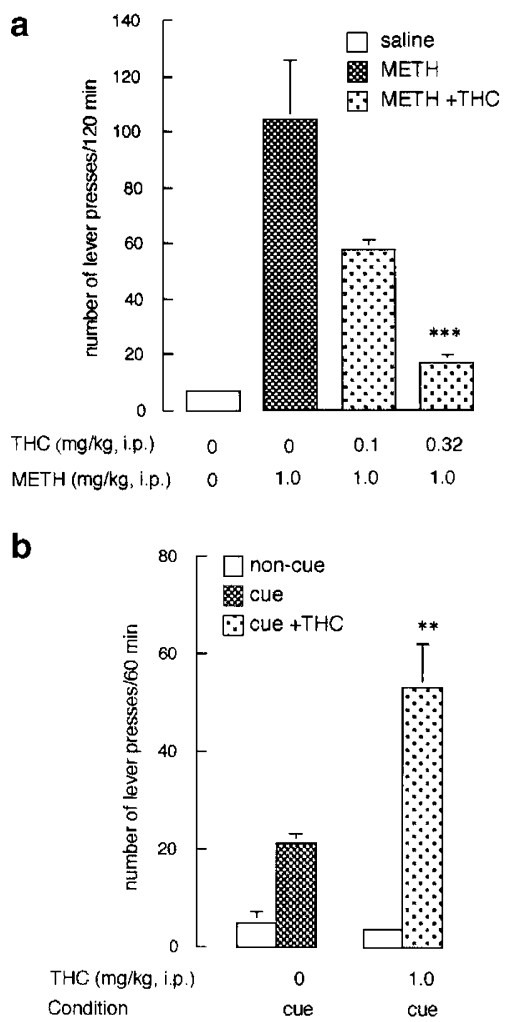

Figure 4 Effects of THC on reinstatement induced by METH-priming and that induced after re-exposure to METH-associated cues. (a) With METH-priming, $0.32 \mathrm{mg} / \mathrm{kg}$ THC showed reinstatement-attenuating effects, as represented by a significant decrease in the number of lever responses. Data represent the average \pm SE number of lever presses, with 5-8 rats per group; **** $p<0.00$ I compared with only METH-treated group. (b) On the other hand, this agonist at $1.0 \mathrm{mg} / \mathrm{kg}$ enhanced the effects of cue on reinstatement. Data represent the average \pm SE number of lever presses; *** $p<0.01$ compared with cue session in only saline-treated group. There were $5-8$ rats in each group.

\section{Effects of THC on METH-Priming- and Cue-Induced Reinstatement}

The data shown in Figure 4a demonstrated the effect of THC on reinstatement of METH-seeking behavior induced by $1 \mathrm{mg} / \mathrm{kg}$ METH. The data were analyzed with a one-way ANOVA, which revealed a significant main effect of treatment $(F(3,23)=13.10, p<0.01)$. Subsequent pairwise analyses (Benferroni/Dunn) showed that $0.32 \mathrm{mg} / \mathrm{kg}$ THC significantly attenuated METH-seeking behavior. In contrast to these results, however, THC at $1 \mathrm{mg} / \mathrm{kg}$ enhanced the effects of cues, as shown by the significant increase in lever press responses $(\mathrm{F}(1,10)=12.20, p<0.01) \quad$ (see Figure $4 b$ ).

\section{Effects of THC Administration During Extinction Phase on Reinstatement}

When THC was given repeatedly after each session from day one through five of extinction, one-way ANOVA revealed a significant main effect of treatment $(\mathrm{F}(2,20)=22.08, p<0.0001)$. Subsequent pairwise analyses (Benferroni/Dunn) showed that $3.2 \mathrm{mg} / \mathrm{kg}$ THC significantly attenuated reinstatement of drug seeking induced by 
METH-priming (see Figure 5a). After single administration of this agonist, $24 \mathrm{~h}$ before METH-priming, one-way ANOVA also revealed a significant effect of treatment $(\mathrm{F}(2,19)=14.6, p<0.0001)$; and post hoc analyses (Benferroni/Dunn) showed that this treatment significantly decreased reinstatement of METH-priming-induced seeking behavior (see Figure 5b). The attenuating effect of THC was also noted after challenging the rats with drug-associated cues. One-way ANOVA revealed a significant main effect of treatment $\quad(\mathrm{F}(1,10)=11.4, \quad p<0.01)$, and subsequent

a

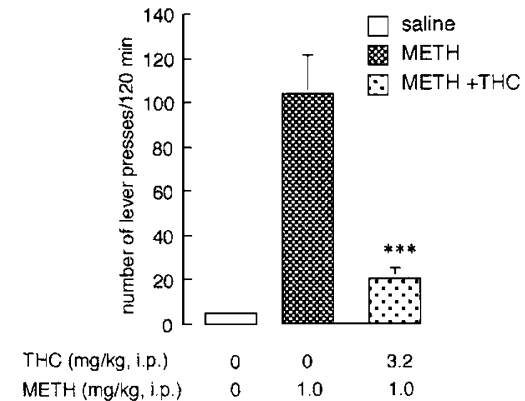

b

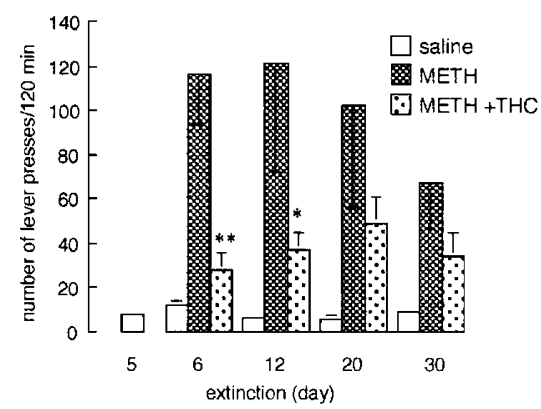

c

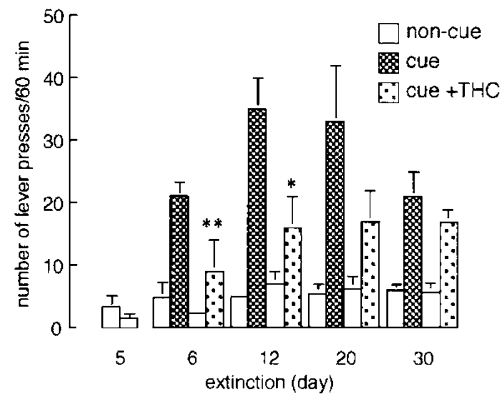

Figure 5 Effects of THC administered during the extinction phase on reinstatement of $\mathrm{METH}$-seeking behavior. (a) Injecting the rats with $\mathrm{THC}$ after each session during extinction period (days I-5 of extinction) suppressed reinstatement of METH-seeking behavior induced by METHpriming on day 6 of extinction. Data represent the average \pm SE of number lever presses, with 5-8 rats per group; **** $p<0.00$ I compared with only METH-treated group. (b) Even single THC pretreatment after the session on day 5 of extinction, $24 \mathrm{~h}$ prior to METH-priming, blocked METH-seeking behavior. Data represent the average \pm SE number of lever presses, with $5-$ 8 rats per group; $* * * 0.0$ I compared with only METH-treated group. (c) Similar results were found in the group challenged with METH-associated cues. Single THC pretreatment after the session on day 5 of extinction produced decreased number of lever press responses. Data represent the average \pm SE number of lever presses, with 4-7 rats per group; $* * * 0.0$ I compared with only cue-treated group. In addition, the effect of such a $\mathrm{THC}$ pretreatment remained significant when the second challenges were repeated on day 12 of extinction, and had the tendency to remain after the third and fourth priming injections, on day 20 and 30 of extinction, respectively. pairwise analyses (Benferroni/Dunn) showed that THC significantly attenuated reinstatement of METH-seeking behavior (see Figure 5c). The significant reinstatementattenuating effects of single THC could still be noted on day 12 of extinction, either after METH-priming injection $(\mathrm{F}(2,15)=5.7, \quad p<0.05) \quad$ or $\quad$ re-exposure to cues $(\mathrm{F}(1,7)=6.7, p<0.05)$. In addition, this THC treatment seemed to suppress reinstatement even after the third and fourth METH/cues challenges.

\section{Effects of Diclofenac on Reinstatement of METH-Seeking Behavior}

The drug-induced reinstatement data were analyzed by oneway ANOVA, which revealed a significant main effect of treatment $(\mathrm{F}(3,22)=4.3, p<0.05)$. Subsequent pairwise analyses (Benferroni/Dunn) showed that diclofenac at 3.2 and $10 \mathrm{mg} / \mathrm{kg}$ produced significant attenuation of reinstatement (see Figure 6a). Significant main effect was also revealed in cue-induced reinstatement data, as analyzed by one-way ANOVA $(\mathrm{F}(2,17)=22.3, p<0.001)$. Post hoc analyses (Benferroni/Dunn) showed that the same doses of diclofenac significantly attenuated reinstatement in rats re-exposed to cues (see Figure 6b). As demonstrated in Figure $6 c$, analyses with one-way ANOVA revealed no significant effect of diclofenac on the response rate of foodself administration $(\mathrm{F}(1,12)=0.12, p<0.74)$.

\section{DISCUSSION}

Reinstatement of METH-seeking behavior was induced by drug-priming and re-exposure to the cues previously accompanying METH taking. SR141716A blocked the reinstatement, and furthermore, a small dose of THC enhanced the effects of a sub-threshold dose of METH. These results may describe hyperactivation of the endocannabinoid system during reinstatement. However, the findings after pretreatment with THC during the extinction phase indicate that prior to the expression of drug-seeking, the endocannabinoid system is inactivated/hyposensitized. Such a hyposensitization following METH self-administration may possibly be related with a decrease in the levels of endogenous cannabinoid ligands or cannabinoid receptors. Thus, chronic cocaine administration has been reported to produce a decrease in 2-arachidonoylglycerol levels in the limbic forebrain area (Gonzalez et al, 2002a). Cocaine was also demonstrated to produce a decrease in $\mathrm{CB} 1$ receptor mRNA in brain areas such as hypothalamus and cerebral cortex (Gonzalez et al, 2002b). Considering the close link between the cannabinoid and dopaminergic systems (Gorriti et al, 1999; Schlicker and Kathmann, 2001), these findings may be consistent with recent electrophysiological evidence of hyposensitivity and hypersensitivity of the dopaminergic system in the nucleus accumbens on day one and day 5 of withdrawal, respectively, following repeated administration of METH (Amano et al, 2002). Thus, pretreatment with THC (before the induction of reinstatement) may prevent further hyposensitization of the endocannabinoid system, and the consequent rebound hypersensitization of the system. This would be manifested 
a
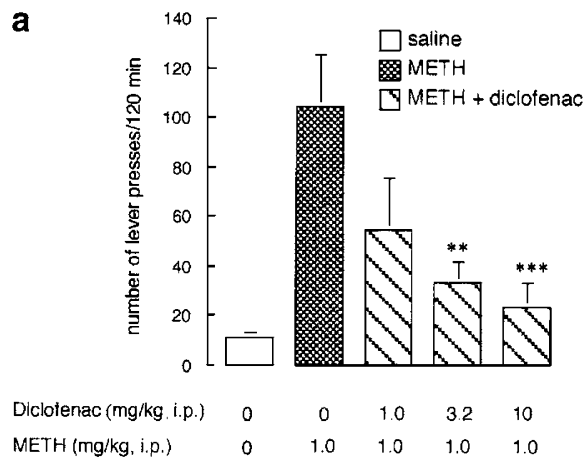

b

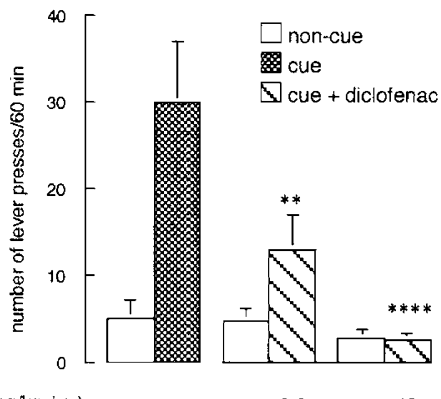

Diclofenac (mg/kg. i.p.) 0

cue

cue

C

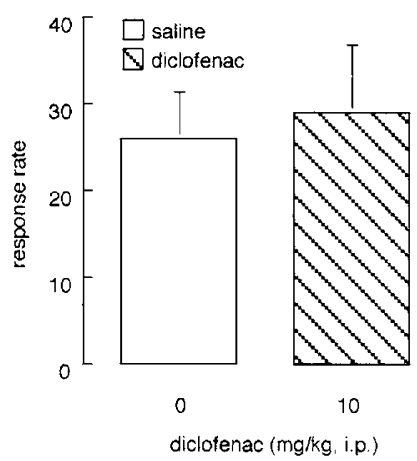

Figure 6 Effects of the cyclooxygenase inhibitor diclofenac on reinstatement of METH-seeking behavior. (a) Given along with METHpriming $30 \mathrm{~min}$ prior to test session, diclofenac suppressed the reinstatement of METH-seeking behavior. Data represent the average \pm SE number of lever presses, with 5-8 rats per group; **⿻丷木 $<0.0$ I, **** $p<0.00$ I compared with only METH-treated group. (b) Pretreatment with diclofenac $30 \mathrm{~min}$ before the second hour (cue phase) of the test session attenuated the reinstatement induced by METH-associated cues. Data represent the average + SE of number of lever presses. There were 5-8 rats in each group; *** $<0.01$, ****** $p<0.000$ I compared with only cuetreated group. (c) Effect of diclofenac on food-reinforced operant responding in the rat. The data are represented as average \pm SE of response rate, during the session lasted until 20 food pellets were delivered or the 15 min experimental time was over. There were 6-8 rats in each group.

in the attenuation of lever press responses (drug-seeking behavior).

In line with the hypothesis of a hypersensitized endocannabinoid system during the expression phase of seeking behavior, THC enhanced the effects of cues on drug-seeking behavior. In contrast to this result, however, THC depressed the reinstatement-inducing effects of $1 \mathrm{mg} / \mathrm{kg} \mathrm{METH}$. Early data indicated that THC at low doses could stimulate motor activity, an effect that was amplified by amphetamine (Evans et al, 1976). In addition, combination of THC with METH or cocaine has been shown to induce stereotyped behaviors (Consroe et al, 1976). Judging from these data, in our study the combination of THC and METH might induce hyperactivity or stereotyped behaviors that masked the lever press behavior. Thus, there might be a possibility that this depressed reinstatement is due to a non-specific effect. Alternatively, this attenuation in reinstatement might be a consequence of the hypothesized inhibitory feedback mechanism that counters the striatal dopamine-cannabinoid pathway (Giuffrida et al, 1999). Indeed, this mechanism might underlie the ameliorating effect of cannabinoid activation in animal models (Beltramo et al, 2000) as well as the patients (Muller-Vahl et al, 2003) of disorders related to the hyperactive dopaminergic tone.

Compelling is the result showing that seeking behavior suppression by THC pretreatment lasted for somewhat long period of time, as indicated by the persistently lower lever response after the second priming/cue presentation on day 12 of extinction. A close relationship between 'relapse' of psychostimulant-seeking behavior and its sensitization has been indicated (De Vries et al, 1998; Vanderschuren et al, 1999; De Vries et al, 2002). On the other hand, repeated cannabinoid agonist treatment has been found to induce sensitization to the psychomotor effects of amphetamine (Gorriti et al, 1999). These findings further indicate the relation between the state of abstinence from METH selfadministration and that of cessation of chronic cannabinoid treatment. Moreover, the expression of cannabinoid withdrawal signs was blocked by THC pretreatment (Lichtman et al, 2001), which may be analogous to the blocking effect of THC pretreatment on the expression of seeking behavior as shown in our study. One recent report demonstrated that spontaneous cannabinoid withdrawal induced proopiomelanocortin gene expression, which was augmented for at least 14 days (this time span coincides well with the duration of reinstatement-suppressing effects of THC in our study) after withdrawal (Oliva et al, 2003). Indeed, changes in gene transcription have been proposed as one of the factors responsible for the vulnerability to drug addiction, including relapse to drug taking (Koob et al, 1998). Meanwhile, THC has been shown to decrease cerebral metabolism, including that in the limbic forebrain areas (Freedland et al, 2002), the brain loci essential to motivational responses, and where many of the gene alterations associated with drug addiction take place (Koob et al, 1998). Decreased metabolism has been shown to parallel the decrease in opioid peptide gene expression, including prodynorphin and proopiomelanocortin (Giraudo et al, 1998; Kim et al, 1999). Considering all this evidence, one may suggest that the long-lasting suppressing effects of THC pretreatment on seeking behavior have a close link with its action on certain gene expression machinery, possibly that of the opioid peptides. The likelihood that such effects originate from its locomotor suppressing action may be ruled out, because the effects of an even higher dose of THC completely disappeared $24 \mathrm{~h}$ after its administration (Whitlow et al, 2002).

The mediating action of the arachidonic acid cascade in several effects of cannabinoids has been shown in a number of animal studies. Indeed, in human subjects, the cycloox- 
ygenase inhibitor, indomethacin, has been demonstrated to antagonize psychological effects of marihuana, including the subjective 'high' and time estimation delay (Perez-Reyes et al, 1991). Furthermore, there is evidence for the involvement of the cascade in the development of stimulant sensitization. The phospholipase A2 inhibitor, quinacrine (Reid et al, 1996), or cyclooxygenase inhibitor, indomethacin (Reid et al, 2002), co-administered during the development phase of sensitization, has been shown to block the behavioral expression of amphetamine and cocaine. A recent study by Kita et al (2000) revealed that treatment with METH induced cyclooxygenase-2 protein expression in the mice striatum; and in turn, ketoprofen prevented against METH-induced striatal neurotoxicity (Asanuma et al, 2003). Furthermore, more recent study indicated a decreased striatal activity of Ca-stimulated phospholipase A2 in autopsied brain of chronic cocaine and METH users (Ross et al, 2002). The latter finding is in line with an earlier result showing that pretreatment with citicoline, which increases the rate of membrane phospholipids synthesis, for two weeks attenuated some measures of craving in cocainedependent subjects (Renshaw et al, 1999). Together with the data showing rich distribution of cannabinoid CB1 (BidautRussel et al, 1990) and prostanoid EP3 (Nakamura et al, 2000) receptors in forebrain loci, it is likely that following repeated METH taking, the striatal arachidonic acid cascade is hyposensitized. This is followed by a rebound hypersensitization of the cascade during the expression of seeking behavior. Such changes in the arachidonic acid cascade may be a down stream consequence of the adaptation of the endocannabinoid system. While this finding gives further support to the important role of the cascade in reinforcing properties of psychostimulants, there have been no data on the effects of diclofenac on operant behavioral performance. To determine the specificity of effect of diclofenac on METH-priming and cue-induced reinstatement of METHseeking behavior, we assessed the effect of the cyclooxygenase inhibitor on the self-administration of food pellets. The lack of effect of diclofenac on the response rate of food self-administration, as result showed, rules out the nonspecificity of its effect. Taken together, these results suggest that the arachidonic acid cascade mediates the role of the endocannabinoid system in the reinstatement of METHseeking behavior.

In summary, with the results presented here, we demonstrated several new insights into the mechanisms behind the reinforcing effects of METH priming and cues as viewed from the standpoint of the endocannabinoidarachidonic acid pathway. Further extending the current view on drug addiction treatment, these results indicate that, besides the potential use of cannabinoid antagonist for the maintenance of drug abstinence, substances which induce the activation of the endocannabinoid tone may be useful for the prevention of relapse to drug use as well as treating drug intoxication in addicts. Yet, the data suggesting reinstatement-blocking effect of THC, if it is considered for clinical application, should be judged in light of some limitations. This is because, like other habit-forming drugs, THC may also produce dependence (Jones et al, 1981; Haney et al, 1999a, b). Furthermore, cannabis consumption has been associated with the risk for psychotic syndromes (Andreasson et al, 1987; Thomas, 1996). It may be necessary, therefore, to develop endocannabinoid-activating substances devoid of such characteristics of THC. Probably, the most applicable in the near future is the use of cyclooxygenase inhibitors as anti-relapse agents.

\section{ACKNOWLEDGEMENTS}

We thank Dr Hiroyuki Tanaka and Prof Yukihiro Shoyama for the isolation and purification of $\Delta^{8}$-tetrahydrocannabinol.

\section{REFERENCES}

Aceto MD, Scates SM, Martin BB (2001). Spontaneous and precipitated withdrawal with a synthetic cannabinoid, WIN 55212-2. Eur J Pharmacol 416: 75-81.

Amano T, Matsubayashi H, Sasa M (2002). Alteration of neuronal activities following repeated administration of stimulants. Jpn J Alcohol Drug Dependence 37: 31-40.

Andreasson S, Allebeck P, Engstrom A, Rydberg U (1987). Cannabis and schizophrenia. A longitudinal study of Swedish conscripts. Lancet 2: 1483-1486.

Anggadiredja K, Yamaguchi T, Tanaka H, Shoyama Y, Watanabe S, Yamamoto T (2003). Prostaglandin E2 attenuates SR141716Aprecipitated withdrawal in tetrahydrocannabinol-dependent mice. Brain Res 966: 47-53.

Asanuma M, Tsuji T, Miyazaki I, Miyoshi K, Ogawa N (2003). Methamphetamine-induced neurotoxicity in mouse brain is attenuated by ketoprofen, a non-steroidal anti-inflammatory drug. Neurosci Lett 352: 13-16.

Beltramo M, de Fonseca FR, Navarro M, Calignano A, Gorriti MA, Grammatikopoulos G et al (2000). Reversal of dopamine $\mathrm{D}(2)$ receptor responses by an anandamide transport inhibitor. J Neurosci 20: 3401-3407.

Bidaut-Russel M, Devane WA, Howlett AC (1990). Cannabinoid receptors and the modulation of cyclic AMP accumulation in the rat brain. J Neurochem 55: 21-26.

Chen JP, Paredes W, Li J, Smith D, Lowinson J, Gardner EL (1990). Delta 9-tetrahydrocannabinol produces naloxone-blockable enhancement of presynaptic basal dopamine efflux in nucleus accumbens of conscious, freely-moving rats as measured by intracerebral microdialysis. Psychopharmacology 102: 156-162.

Cho AK (1990). Ice: a new dosage form of an old drug. Science 249: 631-634.

Consroe P, Jones B, Laird II H (1976). EEG and behavioral effects of delta9-tetrahydrocannabinol in combination with stimulant drugs in rabbits. Psychopharmacology 50: 47-52.

Costa B, Giagnoni G, Colleoni M (2000). Precipitated and spontaneous withdrawal in rats tolerant to anandamide. Psychopharmacology 149: 121-128.

De Vries TJ, Homberg JR, Binnekade R, Raaso H, Schoffelmeer AN (2003). Cannabinoid modulation of the reinforcing and motivational properties of heroin and heroin-associated cues in rats. Psychopharmacology 168: 164-169.

De Vries TJ, Schoffelmeer AN, Binnekade R, Mulder AH, Vanderschuren LJ (1998). Drug-induced reinstatement of heroin- and cocaine-seeking behavior following long-term extinction is associated with expression of behavioural sensitization. Eur J Neurosci 10: 3565-3571.

De Vries TJ, Schoffelmeer AN, Binnekade R, Raaso H, Vanderschuren LJ (2002). Relapse to cocaine- and heroin-seeking behavior mediated by dopamine D2 receptors is time-dependent and associated with behavioral sensitization. Neuropsychopharmacology 26: 18-26.

De Vries TJ, Shaham Y, Homberg JR, Crombag H, Schuurman K, Dieben J et al (2001). A cannabinoid mechanism in relapse to cocaine seeking. Nat Med 7: 1151-1154. 
Evans MA, Harbison RD, Brown DJ, Forney RB (1976). Stimulant actions of delta9-tetrahydrocannabinol in mice. Psychopharmacology 50: 245-250.

Fattore L, Martellota CM, Cossu G, Fratta W (1999). CB1 cannabinoid receptor agonist WIN55,212-2 decreases intravenous cocaine self-administration. Behav Brain Res 104: 141-146.

Freedland CS, Whitlow CT, Miller MD, Porrino LJ (2002). Dosedependent effects of delta9-tetrahydrocannabinol on rates of local cerebral glucose utilization in rat. Synapse 45: 134-142.

Gardner EL (2002). Addictive potential of cannabinoids: the underlying neurobiology. Chem Phys Lipids 121: 267-290.

Gardner EL, Paredes W, Smith D, Donner A, Milling C, Cohen D et al (1988). Facilitation of brain stimulation reward by delta 9-tetrahydrocannabinol. Psychopharmacology 96: 142-144.

Giraudo SQ, Kim EM, Grace MK, Billington CJ, Levine AS (1998). Effect of peripheral 2-DG on opioid and neuropeptide $\mathrm{Y}$ gene expression. Brain Res 792: 136-140.

Giuffrida A, Parsons LH, Kerr TM, Rodriguez de Fonseca F, Navarro M, Piomelli D (1999). Dopamine activation of endogenous cannabinoid signaling in dorsal striatum. Nat Neurosci 2: 358-363.

Gonzalez S, Cascio MG, Fernandez-Ruiz J, Fezza F, Di Marzo V, Ramos JA (2002a). Changes in endocannabinoid contents in the brain of rats chronically exposed to nicotine, ethanol or cocaine. Brain Res 954: 73-81.

Gonzalez S, Fernandez-Ruiz J, Sparpaglione V, Parolaro D, Ramos JA (2002b). Chronic exposure to morphine, cocaine or ethanol in rats produced different effects in brain cannabinoid $\mathrm{CB}(1)$ receptor binding and mRNA levels. Drug Alcohol Depend 66: 77-84.

Gorriti MA, Rodriguez de Fonseca F, Navarro M, Palomo T (1999). Chronic (-)- $\Delta^{9}$-tetrahydrocannabinol treatment induces sensitization to psychomotor effects of amphetmine in rats. Eur $J$ Pharmacol 365: 133-142.

Greberman SB, Wada K (1994). Social and legal factors related to drug abuse in the United States and Japan. Public Health Rep 109: 731-737.

Haney M, Ward AS, Comer SD, Foltin RW, Fischman MW (1999a). Abstinence symptoms following oral THC administration to humans. Psychopharmacology 141: 385-394.

Haney M, Ward AS, Comer SD, Foltin RW, Fischman MW (1999b). Abstinence symptoms following smoked marijuana in humans. Psychopharmacology 141: 395-404.

Hart CL, Ward AS, Haney M, Foltin RW, Fischman MW (2001). Methamphetamine self-administration by humans. Psychopharmacology 157: 75-81.

Hunter SA, Burnstein SH (1997). Receptor mediation in cannabinoid stimulated arachidonic acid mobilization and anandamide synthesis. Life Sci 60: 1563-1573.

Hunter SN, Burnstein SH, Renzulii L (1986). Effects of cannabinoids on the activities of mouse brain lipases. Neurochem Res 11: 1273-1288.

Hutcheson DM, Tzavara ET, Smadja C, Valjent E, Roques BP, Hanoune $\mathrm{J}$ et al (1998). Behavioural and biochemical evidence for signs of abstinence in mice chronically treated with delta-9tetrahydrocannabinol. Br J Pharmacol 125: 1567-1577.

Jones RT, Benowitz NL, Herning RI (1981). Clinical relevance of cannabis tolerance and dependence. J Clin Pharmacol 21: 143S-152S.

Kim EM, Grace MK, Welch CC, Billington CJ, Levine AS (1999). STZ-induced diabetes decreases and insulin normalizes POMC mRNA in arcuate nucleus and pituitary in rats. Am J Physiol 276: R1320-R1326.

Kita T, Shimada K, Mastunari Y, Wagner GC, Kubo K, Nakashima $\mathrm{T}$ (2000). Methamphetamine-induced striatal dopamine neurotoxicity and cyclooxygenase- 2 protein expression in $\mathrm{BALB} / \mathrm{c}$ mice. Neuropharmacology 39: 399-406.

Koob, GF, Sanna PP, Bloom FE (1998). Neuroscience of addiction. Neuron 21: 467-476.
Kozak KR, Rowlinson SW, Marnett LJ (2000). Oxygenation of the endocannabinoid, 2-arachidonylglycerol, to glyceryl prostaglandins by cyclooxygenase-2. J Biol Chem 275: 33744-33749.

Lichtman AH, Fisher J, Martin BR (2001). Precipitated cannabinoid withdrawal is reversed by $\Delta^{9}$-tetrahydrocannabinol or clonidine. Pharmacol Biochem Behav 69: 181-188.

Muller-Vahl KR, Schneider U, Prevedel H, Theloe K, Kolbe H, Daldrup T, Emrich HM (2003). Delta 9-tetrahydrocannabinol (THC) is effective in the treatment of tics in Tourette syndrome: a 6-week randomized trial. J Clin Psychiatry 64: 459-465.

Nakamura K, Kaneko T, Yamashita Y, Hasegawa H, Katoh H, Negishi M (2000). Immunohistochemical localization of prostaglandin EP3 receptor in the rat nervous system. J Comp Neurol 421: 543-569.

Navarro M, Carrera MR, Fratta W, Valverde O, Cossu G, Fattore L et al (2001). Functional interaction between opioid and cannabinoid receptors in drug self-administration. J Neurosci 21: 5344-5350.

Ng Cheong Ton JM, Gerhardt GA, Friedemann M, Etgen AM, Rose GM, Sharpless NS et al (1988). The effects of delta 9-tetrahydrocannabinol on potassium-evoked release of dopamine in the rat caudate nucleus: an in vivo electrochemical and in vivo microdialysis study. Brain Res 451: 59-68.

Oliva JM, Ortiz S, Palomo T, Manzanares J (2003). Behavioral and gene transcription alterations induced by spontaneous cannabinoid withdrawal in mice. J Neurochem 85: 94-104.

Peltier RL, Li DH, Lytle D, Taylor CM, Emmett-Oglesby MW (1996). Chronic d-amphetamine or methamphetamine produces cross-tolerance to the discriminative and reinforcing stimulus effects of cocaine. J Pharmacol Exp Ther 277: 212-218.

Perez-Reyes M, Burnstein SH, White WR, Mc Donald SA, Hicks RE (1991). Antagonism of marihuana effects by indomethacin in humans. Life Sci 48: 507-515.

Reid MS, Ho LB, Hsu K, Fox L, Tolliver BK, Adams JU et al (2002). Evidence for the involvement of cyclooxygenase activity in the development of cocaine sensitization. Pharmacol Biochem Behav 71: 37-54.

Reid MS, Hsu K, Tolliver BK, Crawford CA, Berger SP (1996). Evidence for the involvement of phospholipase A2 mechanisms in the development of stimulant sensitization. J Pharmacol Exp Ther 276: 1244-1256.

Renshaw PF, Daniels S, Lundahl LH, Rogers V, Lukas SE (1999). Short-term treatment with citicoline (CDP-choline) attenuates some measures of craving in cocaine-dependent subjects: a preliminary report. Psychopharmacology 142: 132-138.

Ross BM, Moszczynska A, Peretti FJ, Adams V, Schmunk GA, Kalasinsky KS et al (2002). Decreased activity of brain phospholipid metabolic enzymes in human users of cocaine and methamphetamine. Drug Alcohol Depend 67: 73-79.

Schlicker E, Kathmann M (2001). Modulation of transmitter release via presynaptic cannabinoid receptors. Trends Pharmacol Sci 22: 565-572.

Shimosato K, Ohkuma S (2000). Simultaneous monitoring of conditioned place preference and locomotor sensitization following repeated administration of cocaine and methamphetamine. Pharmacol Biochem Behav 66: 285-292.

Shivachar AC, Martin BR, Ellis EF (1996). Anandamide- and delta9-tetrahydrocannabinol-evoked arachidonic acid mobilization and blockade by SR141716A [ $N$-(Piperidin-1-yl)-5-(4chlorophenyl)-1-(2,4-dichlorophenyl)-4-methyl-1H-pyrazole-3carboximidehydrochloride]. Biochem Pharmacol 51: 669-676.

Thomas H (1996). A community survey of adverse effects of cannabis use. Drug Alcohol Depend 42: 201-207.

Vanderschuren LJMJ, Schoffelmeer ANM, Mulder AH, de Vries TJ (1999). Dopaminergic mechanisms mediating the long-term expression of locomotor sensitization following pre-exposure to morphine or amphetamine. Psychopharmacology 143: 244-253. 
Wartmann M, Campbell D, Subramanian A, Burnstein SH, Davis RJ (1995). The MAP kinase signal transduction pathway is activated by the endogenous cannabinid anandamide. FEBS Lett 359: 133-136.

Whitlow CT, Freedland CS, Porrino LJ (2002). Metabolic mapping of the time-dependent effects of $\Delta^{9}$-tetrahydrocannabinol administration in the rat. Psychopharmacology 161: 129-131.

Woolverton WL, Cervo L, Johanson CE (1984). Effects of repeated methamphetamine administration on methamphetamine selfadministration in rhesus monkey. Pharmacol Biochem Behav 21: 737-741.

Yamaguchi T, Hagiwara Y, Tanaka H, Sugiura T, Waku K, Shoyama Y et al (2001a). Endogenous cannabinoid, 2-arachido-

noylglycerol, attenuates naloxone-precipitated withdrawal signs in morphine-dependent mice. Brain Res 909: 121-126.

Yamaguchi T, Kubota T, Watanabe S, Yamamoto T (2004). Activation of brain prostanoid EP3 receptors via arachidonic acid cascade during behavioral suppression induced by delta8tetrahydrocannabinol. J Neurochem 88: 148-154.

Yamaguchi T, Shoyama Y, Watanabe S, Yamamoto T (2001b). Behavioral suppression induced by cannabinoid is due to activation of the arachidonic acid cascade in rats. Brain Res 889: 149-154.

Yamamoto T, Takada K (2000). Role of cannabinoid receptor in the brain as it relates to drug reward. Jpn J Pharmacol 84: 229-236. 